\title{
A simple coordination complex exhibiting colour change on slight structural modification: Synthesis and crystal structures of violet and yellow forms of [ $\left.\mathrm{Ni}^{\mathrm{iI}}(\mathrm{opda})_{2}(\mathrm{NCS})_{2}\right]$ (opda $=$ orthophenylenediamine $)$
}

\author{
SABBANI SUPRIYA and SAMAR K DAS* \\ School of Chemistry, University of Hyderabad, Hyderabad 500046 \\ e-mail: skdsc@uohyd.ernet.in
}

\begin{abstract}
The violet-coloured compound $\left[\mathrm{Ni}^{\mathrm{II}}(\text { opda })_{2}(\mathrm{NCS})_{2}\right]$ (1) undergoes colour change to strawyellow colour retaining its molecular composition on standing over long period of time at room temperature in the solid state. Compound 1 (violet form) and its yellow-form $\left[\mathrm{Ni}^{\mathrm{II}}(\text { opda })_{2}(\mathrm{NCS})_{2}\right]$ (2) (opda $=$ orthophenylenediammine) have been characterized by routine spectroscopic methods and single crystal X-ray diffraction analysis. Compound 1 crystallizes in monoclinic space group $P 2_{1} / c$ and its yellow form (compound 2) retains same space group. Their crystal structures show an intricate supramolecular network based on $\mathrm{N}-\mathrm{H} \cdots \mathrm{S}$ hydrogen bonds, that involve amine and thiocyanate groups coordinated to nickel(II).
\end{abstract}

Keywords. Orthophenylenediamine; nickel complexes; crystal structures; intricate hydrogen bonding networks.

\section{Introduction}

The conformational change of five- and sixmembered diamine chelate rings in metal complexes are well-documented. ${ }^{1-9}$ Phase changes of some nickel(II) diamine complexes have been reported, on the basis of an analysis of the general stereochemistry of the chelate rings in complex ions. However, any discussion relating to the conformations of complexes is speculative, unless supported by crystalstructure analysis. In 1979, Grenthe and co-worker. reported thermochromism of bis $(\mathrm{NN}$-diethylethane1,2-diamine) copper(II) perchlorate on the basis of single crystal X-ray structure analysis, where the thermochromism was described as due to sudden decrease in strength of the in-plane ligand field caused by conformational changes in the ring system. ${ }^{10}$ Some of the diamine complexes of nickel (II) thiocyanate, exhibiting solid state phase transition, are reported but the crystal structures for both the forms were not available. ${ }^{11-14}$ Here we report synthesis and structural characterization of compound $\left[\mathrm{Ni}^{\mathrm{II}}(\text { opda })_{2}(\mathrm{NCS})_{2}\right]$ (1). The violet crystals of compound 1, on standing for a long time (around

*For correspondence
3 months) change their colour to straw-yellow. The crystal structure of this yellow form (compound 2) is essentially comparable to that of violet form (compound 1) crystals. We have analysed the crystal structures of both compounds $\mathbf{1}$ and $\mathbf{2}$ and we have shown here that slight structural modification of $\mathbf{1}$ causes its colour change from violet to yellow with the formation of compound $\mathbf{2}$. We have also described the thermochromic properties of compound 1 .

\section{Experimental}

\subsection{Materials and methods}

All the chemicals of reagent grade were used without any further purification. The distilled water was used throughout the work.

Infrared (with $\mathrm{KBr}$ pellets) spectra were recorded using a JASCO FT/IR-5300 FT-IR spectrophotometer. The elemental analysis data were obtained with Flash 1112 SERIES EA analyser. The reflectance UV-visible spectra were measured using a 3101 Philips spectrophotometer. The solid powders of samples were spreaded over grease on a glass plate and the diffuse reflectance spectra obtained were the Kubelka-Munk corrected with grease (on glass plate) back ground. 
2.2 Synthesis of compound

$\left[\mathrm{Ni}^{\mathrm{II}}\left\{\mathrm{C}_{6} \mathrm{H}_{4}\left(\mathrm{NH}_{2}\right)_{2}\right\}_{2}(\mathrm{NCS})_{2}\right](\mathbf{1})$

$1 \mathrm{~g} \mathrm{NiCl}_{2}$ was dissolved in $7 \mathrm{~mL}$ ethanol. To this solution KSCN solution (prepared by dissolving $0.66 \mathrm{~g}$ $\mathrm{KSCN}$ in $7 \mathrm{~mL}$ ethanol by heating) was added; this immediately resulted in white precipitate. This mixture was allowed to cool when white solid $\mathrm{KCl}$ separated out and it was separated via filtration; the green colour filtrate obtained was treated with orthophenylenediamine solution $(0 \cdot 15 \mathrm{~g}$ in $10 \mathrm{~mL}$ ethanol). Violet colour crystals of compound 1 separated on standing over a period of 5 to $6 \mathrm{~h}$. The single crystals suitable for X-ray analysis were obtained from a relatively diluted solution. Yield: $63 \%$ based on nickel. Anal. Calcd (found) for $\mathrm{C}_{12} \mathrm{H}_{16} \mathrm{~N}_{6} \mathrm{NiS}_{2}$ (M.W. 391): C, 39.26 (40.13); H, 4.4 (4.56); N, 22.9 (24.12); S, 17.47 (16.01). IR ( $\mathrm{KBr}$ pellet, $\left.v / \mathrm{cm}^{-1}\right)$ : $3302 m, 3200 w, 2114 v s, 1604 s, 1562 s, 1495 s$, $1246 m, 1209 m, 1176 w, 1153 w, 1105 v, 1006 v s$, $756 v s, 601 s, 499 m, 464 w, 437 s$.

\subsection{Yellow form of $\left[\mathrm{Ni}^{\mathrm{II}}\left\{\mathrm{C}_{6} \mathrm{H}_{4}\left(\mathrm{NH}_{2}\right)_{2}\right\}_{2}(\mathrm{NCS})_{2}\right]$}

Violet colour compound 1, on standing for long time ( $\sim 3$ months) at an open ambient condition, converts to yellow compound 2. Compound 2 can also be obtained instantaneously from 1 by heating the crystals of compound 1 in the temperature range of 110 to $120^{\circ} \mathrm{C}$. Compound 1 , on exposure to sunlight, also results in the formation of compound 2. However, crystals of compound $\mathbf{2}$, obtained in latter two cases (thermally and photochemically), are not suitable for single crystal X-ray structure determination. The compound 2, obtained through anyone of three ways, has the identical IR and CHNS analysis as those of compound 1. Yield: 100\%. Anal. Calcd. (found) (\%) for $\mathrm{C}_{12} \mathrm{H}_{16} \mathrm{~N}_{6} \mathrm{NiS}_{2}$ (M.W. 391): C, 39.26 $(41.13) ; \mathrm{H}, 4.4(4 \cdot 16) ; \mathrm{N}, 22.9(23.16) ; \mathrm{S}, 17.47$ (18.01). IR (KBr pellet, $v / \mathrm{cm}^{-1}$ ): $3302 \mathrm{~m}, 3200 \mathrm{w}$, $2114 v s, 1604 s, 1562 s, 1495 s, 1246 \mathrm{~m}, 1209 \mathrm{~m}$, $1176 w, 1153 w, 1105 v, 1006 v s, 756 v s, 601 s$, $499 m, 464 w, 437 s$.

\section{$2.4 \quad$ X-ray crystallography}

X-ray data for complexes 1 and $\mathbf{2}$ were collected on Bruker-nonius SMART APEX CCD single crystal diffractometer using graphite monochromated Mo-K $\alpha(0.71073 \AA)$. The SMART software was used for the intensity data acquisition and the
SAINT PLUS software was used for data extraction. In each case, Data reduction was done by SAINTPLUS, ${ }^{15}$ absorption correction by using an empirical method SADABS, ${ }^{16}$ structure solution using SHELXS-97, ${ }^{17}$ and refined using SHELXL97. ${ }^{18}$ The SHELX-97 was used for the structure solution and least square refinement on $F^{2}$. All the non-hydrogen atoms were refined anisotropically. The hydrogen atoms were included in the structure factor calculated by using a riding model. The DIAMOND software was used for molecular graphics. The crystallographic data for compounds 1 and 2 are summarized in table 1. CCDC-768119 contains the supplementary crystallographic data for complex 1. This can be obtained free of charge on application to the Director, CCDC, 12 Union Road, Cambridge CB21EZ, UK (fax: +44 1223336 033; e-mail: deposit@ecdc.cam.ac.uk or www: http://www.ccdc. cam.ac.uk). The unit cell parameters of the yellow form of compound $\mathbf{1}$, what we name here as compound 2 , is essentially comparable to those of compound 1 (purple coloured crystals). This is why we did not deposit the crystal data of this yellow crystals to CCDC. However, cif files of both compounds $\mathbf{1}$ and $\mathbf{2}$ are provided with supporting information.

\section{Results and discussion}

Compound 1 was prepared by treating NiSCN solution (prepared insitu by treating the saturated ethanolic solution of $\mathrm{NiCl}_{2}$ with ethanolic solution of $\mathrm{KSCN}$ whereby a white precipitate of $\mathrm{KCl}$ separated out which was separated from the green filterate) with ethanolic solution of ortho-phenylenediamine. Compound 1 crystallizes as violet block shaped crystal. Violet colour compound $\left[\mathrm{Ni}^{\mathrm{II}}\left\{\mathrm{C}_{6} \mathrm{H}_{4}\left(\mathrm{NH}_{2}\right)_{2}\right\}_{2}\right.$ $\left.(\mathrm{NCS})_{2}\right](1)$, on heating or on exposure to sunlight or standing over long period of time at room temperature, transforms to a yellow coloured compound $\left[\mathrm{Ni}^{\mathrm{II}}\left\{\mathrm{C}_{6} \mathrm{H}_{4}\left(\mathrm{NH}_{2}\right)_{2}\right\}_{2}(\mathrm{NCS})_{2}\right] 2$ (which is a isomeric form of compound 1 ). The crystal structure analysis performed on compounds 1 and $\mathbf{2}$ show that both of the complexes have overall similar structural features, consisting of discrete $\left[\mathrm{Ni}^{\mathrm{II}}\left\{\mathrm{C}_{6} \mathrm{H}_{4}\left(\mathrm{NH}_{2}\right)_{2}\right\}_{2}\right.$ $(\mathrm{NCS})_{2}$ ]. There are some differences in structural features (e.g. bond lengths and angles) between compounds 1 and $\mathbf{2}$, which probably account for this colour change from violet to yellow.

The overall molecular structures of compounds 1 and $\mathbf{2}$ are comparable and therefore are discussed on 
Table 1. Crystal data and structure refinement for compounds $\mathbf{1}$ and $\mathbf{2 .}$

\begin{tabular}{lll}
\hline & Compound 1 & Compound 2 \\
\hline Empirical formula & $\mathrm{C}_{12} \mathrm{H}_{16} \mathrm{~N}_{6} \mathrm{NiS}_{2}$ & $\mathrm{C}_{12} \mathrm{H}_{16} \mathrm{~N}_{6} \mathrm{NiS}_{2}$ \\
$F_{w}$ & $391 \cdot 16$ & $391 \cdot 16$ \\
$T(\mathrm{~K})$ & $273(2)$ & $273(2)$ \\
$\lambda(\AA)$ & $0 \cdot 71073$ & $0 \cdot 71073$ \\
Crystal system & Monoclinic & Monoclinic \\
space group & $P 2_{1} / c$ & $P 2_{1} / c$ \\
$a(\AA)$ & $8 \cdot 5660(9)$ & $8 \cdot 5693(7)$ \\
$b(\AA)$ & $13 \cdot 6479(14)$ & $13 \cdot 6278(11)$ \\
$c(\AA)$ & $7 \cdot 5045(8)$ & $7 \cdot 4998(6)$ \\
$\alpha\left({ }^{\circ}\right)$ & 90 & 90 \\
$\beta\left({ }^{\circ}\right)$ & $93 \cdot 076(2)$ & $93 \cdot 1440(10)$ \\
$\gamma\left({ }^{\circ}\right)$ & 90 & 90 \\
$V\left(\AA^{3}\right)$ & $876 \cdot 07(16)$ & $874 \cdot 51(12)$ \\
$Z$ & 2 & 2 \\
$\rho_{\text {calc }}\left(\mathrm{Mg} \mathrm{m}^{-3}\right)$ & $1 \cdot 483$ & $1 \cdot 485$ \\
$\mu\left(\mathrm{mm}{ }^{-1}\right)$ & $1 \cdot 352$ & $1 \cdot 354$ \\
$F(000)$ & 404 & 404 \\
$2 \theta$ range/deg & $2 \cdot 81$ to $26 \cdot 04$ & $2 \cdot 38$ to $25 \cdot 00$ \\
Reflections collected/unique & $8672 / 1680$ & $8231 / 1535$ \\
Parameters & 122 & 122 \\
$R_{\text {int }}$ & $0 \cdot 0304$ & $0 \cdot 0668$ \\
$T_{\text {max }}, T_{\text {min }}$ & $0 \cdot 9233,0 \cdot 7737$ & $0 \cdot 9231,0 \cdot 3445$ \\
$G O F\left(F^{2}\right)$ & $1 \cdot 021$ & $0 \cdot 969$ \\
$R 1, w R 2[I>2 \sigma(I)]$ & $0 \cdot 0401 / 0 \cdot 0983$ & $0 \cdot 0466 / 0 \cdot 0667$ \\
$R 1, w R 2($ all data $)$ & $0 \cdot 0462 / 0 \cdot 1021$ & $0 \cdot 0770 / 0 \cdot 0739$ \\
Largest diff. peak and hole $\left(\mathrm{eA}^{-3}\right)$ & $0 \cdot 644$ and $-0 \cdot 310$ & $0 \cdot 683$ and $-0 \cdot 238$ \\
\hline
\end{tabular}
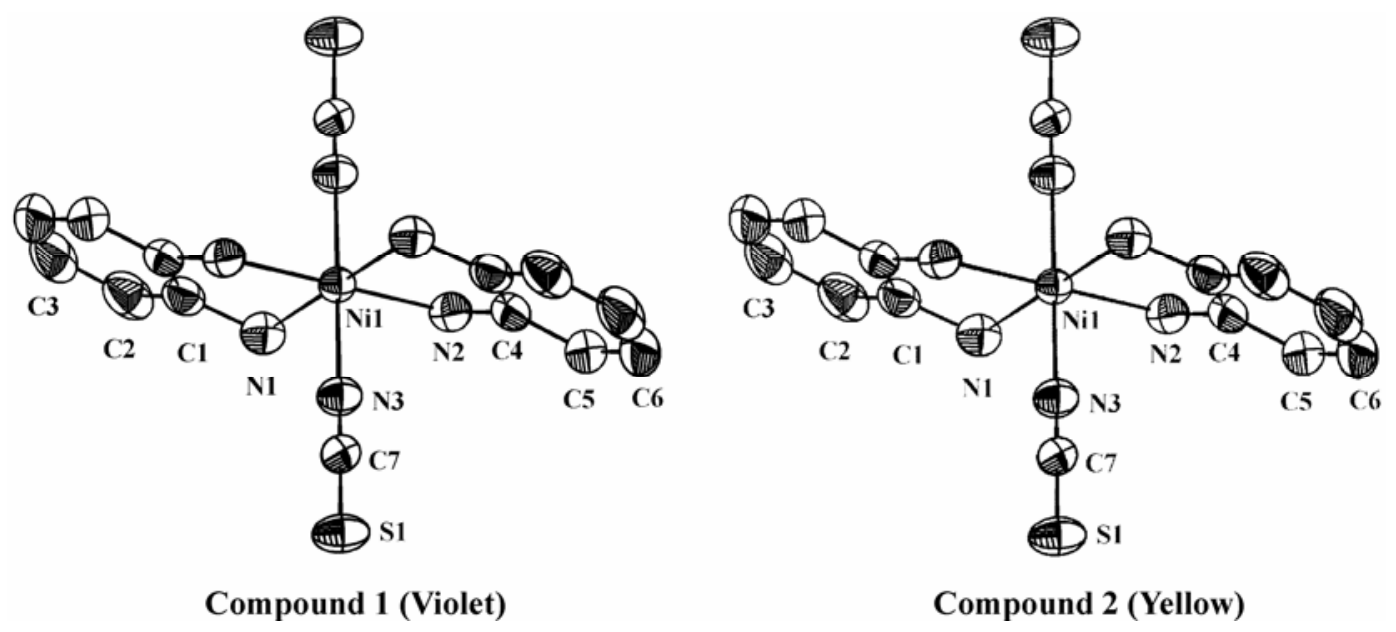

Figure 1. Thermal ellipsoidal plots of compounds $\mathbf{1}$ and $\mathbf{2}$.

a common platform. The crystal structure consists of single monomeric complex, in which a nickel atom is octahedrally coordinated with four amine nitrogens (from two OPDA ligands) that define equatorial positions and the axial positions are filled by the nitrogen atoms coming from two different thiocyanate ligands (figure 1). The thiocyanate ligands generally exhibit different binding modes in its metal complexes like S-bonded, N-bonded, bridging or ionic, etc. ${ }^{19}$ The bonding mode of thiocyanate ligand (whether S-bonding or N-bonding) is dictated by the hard/soft acid/base principle. Nickel ion being hard acid prefers $\mathrm{N}$-bonding where as in the case of platinium thiocyanate complexes, the coordina- 
Table 2. Hydrogen bonding parameters for compounds 1 and 2.

\begin{tabular}{|c|c|c|c|c|}
\hline \multicolumn{5}{|l|}{ Compound 22} \\
\hline N1-H1B $\cdots$ S $1 \# 2$ & $0 \cdot 67(4)$ & $2 \cdot 79(4)$ & $3 \cdot 425(3)$ & $158(4)$ \\
\hline $\mathrm{N} 2-\mathrm{H} 2 \mathrm{~A} \cdots \mathrm{S} 1 \# 3$ & $0.77(3)$ & $2 \cdot 74(3)$ & $3 \cdot 483(3)$ & $165(3)$ \\
\hline \multicolumn{5}{|l|}{ Compound 23} \\
\hline N1-H1B $\cdots$ S1\#2 & $0 \cdot 79(4)$ & $2 \cdot 67(4)$ & $3 \cdot 411(5)$ & $158(4)$ \\
\hline $\mathrm{N} 2-\mathrm{H} 2 \mathrm{~A} \cdots \mathrm{S} 1 \# 3$ & $0.78(4)$ & $2 \cdot 72(4)$ & $3 \cdot 481(4)$ & $165(4)$ \\
\hline
\end{tabular}

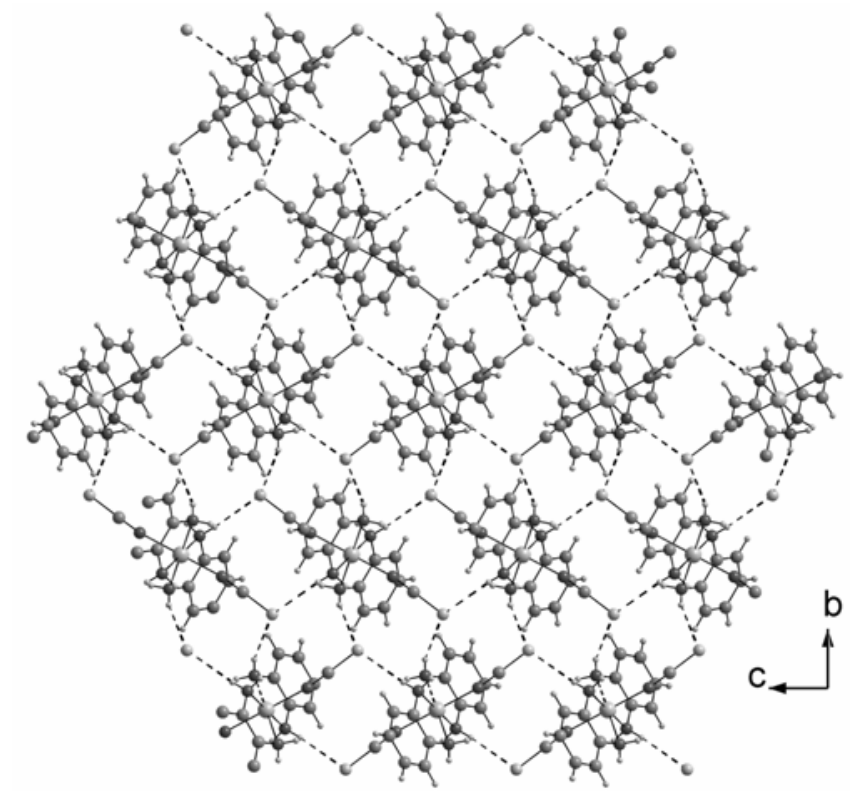

Figure 2. The supramolecular network, formed in the crystal structure of compound 1 (viewed looking down to crystallographic $a$-axis).

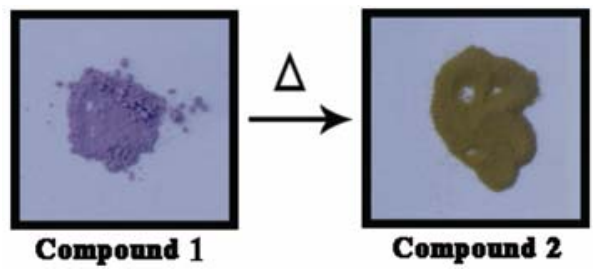

Scheme 1.

tion of $\mathrm{S}$ donor site is preferred. The $\mathrm{N}$-coordinated thiocyanate ligand aligns straight, where as, the S-coordinated form exhibits bend conformation. ${ }^{20}$

In the crystal structure, each metal complex forms eight $\mathrm{N}-\mathrm{H} \cdots \mathrm{S}$ hydrogen bonds with its surroundings; two sulfur atoms of each metal complex accept four hydrogen bonds. The four hydrogen atoms from two amine ligands form the rest four hydrogen bonds. Based on these interactions, a supramolecular net- work has been stabilized as shown in figure 2. The relevant hydrogen bonding parameters are described in table 2 .

\subsection{Solid state properties of compound 1}

Compound 1, on heating in the temperature range of 110 to $120^{\circ} \mathrm{C}$, undergoes a colour change from violet to yellow as shown in scheme 1. Complex 1 has an absorption band at around $436 \mathrm{~nm}$ (see figure 3). On heating, the absorption peak shifts from $436 \mathrm{~nm}$ to $385 \mathrm{~nm}$. The IR spectrum of the resulting yellow colour compound 2 was identical to that of compound $\mathbf{1}$. Conversion of compound 1 to 2 can also be driven by sun light; but in both cases (thermally and photochemically) converted crystals loose their single crystallinity. Compound $\mathbf{1}$, on standing at room temperature for long time (over a period of month) was converted to compound 2. Crystals obtained this way, were suitable for crystal structure determination. In order to understand the basis for this colour change from violet to yellow (thermochromism), the $\mathrm{X}$-ray diffraction studies of both violet crystals (compound 1) and yellow compound (2) were taken up. Surprisingly, the unit cell parameters of the converted yellow colour compound $\mathbf{2}$ were almost identical to those of compound 1. Even the conversion was visible by the colour change of the system (the electronic absorption spectral features are also different, see figure 3), the space group of the transformed/converted product remained similar (see table 1). Therefore, the possibility of linkage isomerization (in terms of thiocyanate ligand) in the complex 1 was ruled out. We, then, attempted to elucidate this colour change from violent to yellow (on heating or long standing) by taking conformational isomerization into consideration, which may arise owing to the difference in conformational change of the chelate ring that involves OPDAamine ligands. These sorts of examples of colour 
change (upon heating), that are associated with slight change in the conformation of the chelate ring in a coordination complex, are well documented in literature.$^{11-14}$ The careful examination of coordination environment around nickel ion in both the complexes 1 and $\mathbf{2}$ in a comparative manner would be useful to understand the process of thermochromism in compound 1 .

\subsection{Comparison of bond lengths and angles from} the molecular structures of compounds $\mathbf{1}$ and $\mathbf{2}$

Thermochromic compounds have at least two different electronic states with two different colours. This implies that the two states can be switched by illumination as well as by thermal excitation. However, most of the solid state thermochromic complexes do not show a photo-induced change in colour. The present compound $\left[\mathrm{Ni}^{\mathrm{II}}\left\{\mathrm{C}_{6} \mathrm{H}_{4}\left(\mathrm{NH}_{2}\right)_{2}\right\}_{2}(\mathrm{NCS})_{2}\right]$ (1), which is violet in colour, undergoes colour change to yellow both by heat and light. The complex 1 has an absorption band at $\sim 436 \mathrm{~nm}$, which can be assigned to the $d-d$ transition. On heating compound 1 at around $110-120^{\circ} \mathrm{C}$, the absorption peak shifts to $385 \mathrm{~nm}$. Hence, the phase transition is brought about by the change in the conformation of metal coordinated ligands. In both compounds $\mathbf{1}$ and $\mathbf{2}$, the four coordinated $\mathrm{N}$ atoms (from two OPDA ligands) and the central nickel ion are positioned in a perfect plane as shown in the following equations and parameters:

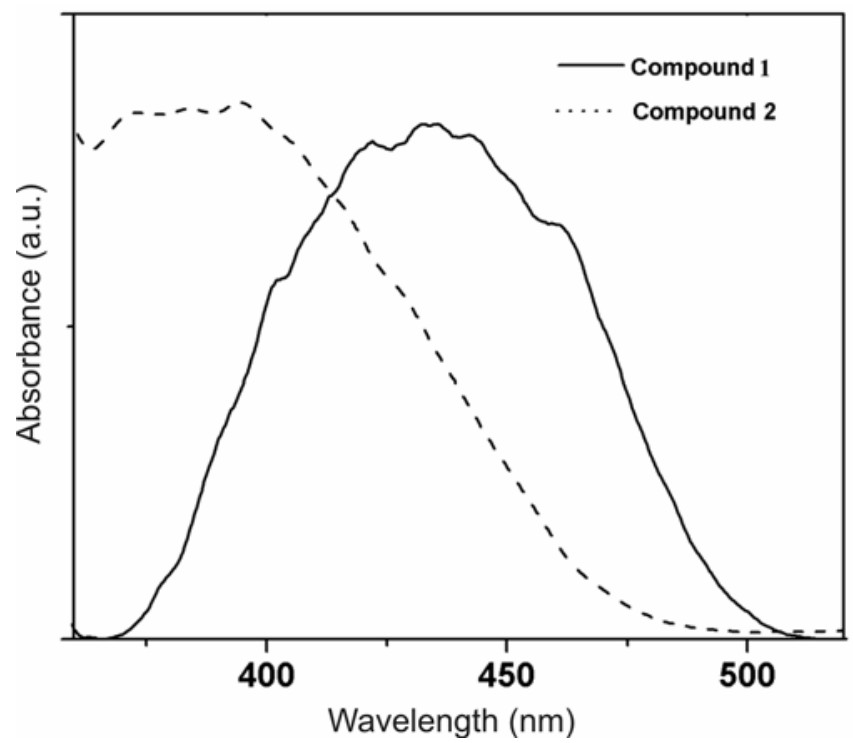

Figure 3. Electronic absorbance spectra of compounds 1 (solid line) and 2 (doted line). 3.2a In compound 1: The plane (I) $\mathrm{Ni}(1), \mathrm{N}(1)$, $\mathrm{N}(2) \# 1, \mathrm{~N}(1) \# 1$ and $\mathrm{N}(2)$ (see figure 1) is defined by $-1.5844(0.0114) x+6.4209(0.0200) y+6.5402$ $(0.0061) z=6.4209(0.0200)$ equation.

The plane (II) (C4, C5, C5, C1\#1, C2\#1 and C3\#1) is defined by $-4.9263(0.0093) x+4.6749(0.0178) y+$ $5.7988(0.0068) z=3.9640(0.0202)$ equation

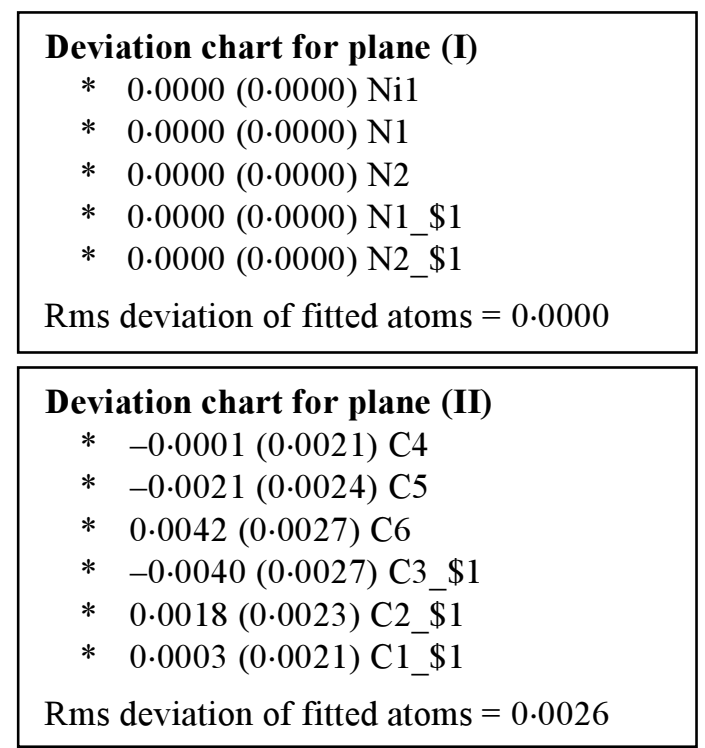

The angle between plane (II) $(\mathrm{C} 4, \mathrm{C} 5, \mathrm{C} 5, \mathrm{C} 1 \# 1$, $\mathrm{C} 2 \# 1$ and $\mathrm{C} 3 \# 1)$ to plane (I) $(\mathrm{Ni1}, \mathrm{N} 1, \mathrm{~N} 2, \mathrm{~N} 1 \# 1$, $\mathrm{N} 2 \# 1$ ) is $24 \cdot 70$.

3.2b In Compound 2: The plane (I) $\mathrm{Ni}(1), \mathrm{N}(1)$, $\mathrm{N}(2) \# 1, \mathrm{~N}(1) \# 1$ and $\mathrm{N}(2)$ is described by 1.6012 $(0.0164) x+6.3383(0.0284) y-6.5568 \quad(0.0085) z=$ $1.6012(0.0164)$ equation.

The plane (II) is described by $4.9207(0.0110) x+$ $4.6347(0.0216) y-5.8130(0.0078) z=5.6284(0.0169)$ equation.

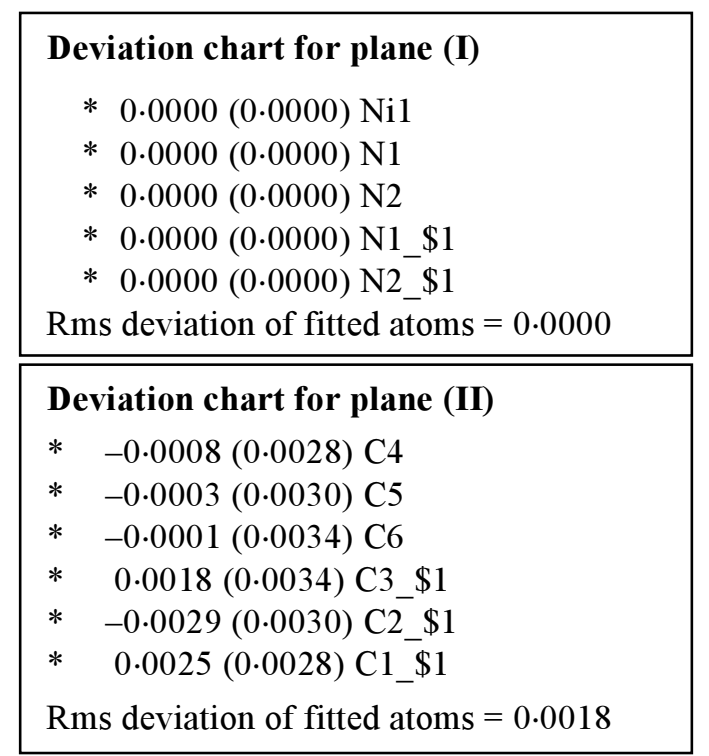


Table 3. The comparison of bond lengths and bond angles in compounds 1 and 2.

\begin{tabular}{|c|c|c|c|}
\hline & Compound $\mathbf{1}$ & Compound 2 & Deviation \\
\hline \multicolumn{4}{|c|}{ Comparison of bond lengths } \\
\hline $\mathrm{C}(4)-\mathrm{C}(1) \# 1$ & $1 \cdot 377(4)$ & $1 \cdot 381(5)$ & $0 \cdot 004$ \\
\hline $\mathrm{C}(4)-\mathrm{C}(5)$ & $1 \cdot 393(5)$ & $1 \cdot 385(5)$ & $-0 \cdot 008$ \\
\hline $\mathrm{C}(4)-\mathrm{N}(2)$ & $1 \cdot 442(4)$ & $1 \cdot 451(5)$ & $0 \cdot 009$ \\
\hline $\mathrm{C}(5)-\mathrm{C}(6)$ & $1 \cdot 376(5)$ & $1 \cdot 359(7)$ & $-0 \cdot 02$ \\
\hline $\mathrm{C}(6)-\mathrm{C}(3) \# 1$ & $1 \cdot 361(6)$ & $1 \cdot 368(7)$ & $0 \cdot 007$ \\
\hline $\mathrm{C}(1)-\mathrm{C}(4) \# 1$ & $1 \cdot 377(4)$ & $1 \cdot 381(5)$ & 0.004 \\
\hline $\mathrm{C}(1)-\mathrm{C}(2)$ & $1 \cdot 395(4)$ & $1 \cdot 376(5)$ & $-0 \cdot 019$ \\
\hline $\mathrm{C}(1)-\mathrm{N}(1)$ & $1 \cdot 440(4)$ & $1 \cdot 439(6)$ & $-0 \cdot 001$ \\
\hline $\mathrm{C}(2)-\mathrm{C}(3)$ & $1 \cdot 386(6)$ & $1 \cdot 392(6)$ & $0 \cdot 006$ \\
\hline $\mathrm{C}(3)-\mathrm{C}(6) \# 1$ & $1 \cdot 361(6)$ & $1 \cdot 368(7)$ & 0.007 \\
\hline $\mathrm{C}(7)-\mathrm{N}(3)$ & $1 \cdot 140(3)$ & $1 \cdot 139(4)$ & $-0 \cdot 001$ \\
\hline $\mathrm{C}(7)-\mathrm{S}(1)$ & $1 \cdot 650(3)$ & $1 \cdot 648(4)$ & $-0 \cdot 002$ \\
\hline $\mathrm{N}(2)-\mathrm{Ni}(1)$ & $2 \cdot 088(2)$ & $2 \cdot 086(4)$ & $-0 \cdot 002$ \\
\hline $\mathrm{N}(1)-\mathrm{Ni}(1)$ & $2 \cdot 090(3)$ & $2 \cdot 093(4)$ & $0 \cdot 003$ \\
\hline $\mathrm{N}(3)-\mathrm{Ni}(1)$ & $2 \cdot 074(2)$ & $2 \cdot 077(3)$ & $0 \cdot 003$ \\
\hline $\mathrm{Ni}(1)-\mathrm{N}(3) \# 1$ & $2 \cdot 074(2)$ & $2 \cdot 077(3)$ & $0 \cdot 003$ \\
\hline $\mathrm{Ni}(1)-\mathrm{N}(2) \# 1$ & $2 \cdot 088(2)$ & $2 \cdot 086(4)$ & $-0 \cdot 002$ \\
\hline $\mathrm{Ni}(1)-\mathrm{N}(1) \# 1$ & $2 \cdot 090(3)$ & $2 \cdot 093(4)$ & $0 \cdot 003$ \\
\hline \multicolumn{4}{|c|}{ Deviations in the bond angles } \\
\hline $\mathrm{C}(1) \# 1-\mathrm{C}(4)-\mathrm{C}(5)$ & $120 \cdot 0(3)$ & $120 \cdot 2(4)$ & $0 \cdot 2$ \\
\hline $\mathrm{C}(1) \# 1-\mathrm{C}(4)-\mathrm{N}(2)$ & $117 \cdot 7(3)$ & $117 \cdot 1(4)$ & $-0 \cdot 6$ \\
\hline $\mathrm{C}(5)-\mathrm{C}(4)-\mathrm{N}(2)$ & $122 \cdot 3(3)$ & $122 \cdot 7(4)$ & $0 \cdot 4$ \\
\hline $\mathrm{C}(6)-\mathrm{C}(5)-\mathrm{C}(4)$ & $119 \cdot 8(4)$ & $120 \cdot 4(5)$ & $0 \cdot 6$ \\
\hline $\mathrm{C}(3) \# 1-\mathrm{C}(6)-\mathrm{C}(5)$ & $120 \cdot 6(4)$ & $119 \cdot 7(5)$ & $-0 \cdot 9$ \\
\hline $\mathrm{C}(4) \# 1-\mathrm{C}(1)-\mathrm{C}(2)$ & $119 \cdot 7(3)$ & $119 \cdot 7(4)$ & $0 \cdot 0$ \\
\hline $\mathrm{C}(4) \# 1-\mathrm{C}(1)-\mathrm{N}(1)$ & $117 \cdot 6(3)$ & $117 \cdot 7(4)$ & $0 \cdot 1$ \\
\hline $\mathrm{C}(2)-\mathrm{C}(1)-\mathrm{N}(1)$ & $122 \cdot 7(3)$ & $122 \cdot 5(4)$ & $-0 \cdot 2$ \\
\hline $\mathrm{C}(3)-\mathrm{C}(2)-\mathrm{C}(1)$ & $119 \cdot 6(4)$ & $119 \cdot 1(5)$ & $-0 \cdot 5$ \\
\hline $\mathrm{C}(6) \# 1-\mathrm{C}(3)-\mathrm{C}(2)$ & $120 \cdot 5(3)$ & $121 \cdot 0(5)$ & $0 \cdot 5$ \\
\hline $\mathrm{N}(3)-\mathrm{C}(7)-\mathrm{S}(1)$ & $178 \cdot 3(3)$ & $178 \cdot 2(4)$ & $-0 \cdot 1$ \\
\hline $\mathrm{C}(4)-\mathrm{N}(2)-\mathrm{Ni}(1)$ & $108 \cdot 66(19)$ & $109 \cdot 0(3)$ & $0 \cdot 34$ \\
\hline $\mathrm{C}(1)-\mathrm{N}(1)-\mathrm{Ni}(1)$ & $108 \cdot 77(19)$ & $109 \cdot 1(3)$ & $0 \cdot 33$ \\
\hline $\mathrm{C}(7)-\mathrm{N}(3)-\mathrm{Ni}(1)$ & $172 \cdot 5(2)$ & $171 \cdot 9(3)$ & $-0 \cdot 6$ \\
\hline $\mathrm{N}(3) \# 1-\mathrm{Ni}(1)-\mathrm{N}(3)$ & $180 \cdot 0$ & $179.998(1)$ & -0.002 \\
\hline $\mathrm{N}(3) \# 1-\mathrm{Ni}(1)-\mathrm{N}(2)$ & $91 \cdot 04(11)$ & $91 \cdot 00(15)$ & $-0 \cdot 04$ \\
\hline $\mathrm{N}(3)-\mathrm{Ni}(1)-\mathrm{N}(2)$ & $88 \cdot 96(11)$ & $89 \cdot 00(15)$ & $0 \cdot 04$ \\
\hline $\mathrm{N}(3) \# 1-\mathrm{Ni}(1)-\mathrm{N}(2) \# 1$ & $88 \cdot 96(11)$ & $89 \cdot 00(15)^{\prime}$ & $0 \cdot 04$ \\
\hline $\mathrm{N}(3)-\mathrm{Ni}(1)-\mathrm{N}(2) \# 1$ & $91 \cdot 04(11)$ & $91 \cdot 00(15)$ & $-0 \cdot 04$ \\
\hline $\mathrm{N}(2)-\mathrm{Ni}(1)-\mathrm{N}(2) \# 1$ & $180 \cdot 0$ & $180 \cdot 0(2)$ & $0 \cdot 0$ \\
\hline $\mathrm{N}(3) \# 1-\mathrm{Ni}(1)-\mathrm{N}(1)$ & $89 \cdot 47(11)$ & $89 \cdot 34(15)$ & $-0 \cdot 13$ \\
\hline $\mathrm{N}(3)-\mathrm{Ni}(1)-\mathrm{N}(1)$ & $90 \cdot 53(11)$ & $90 \cdot 66(15)$ & $0 \cdot 13$ \\
\hline $\mathrm{N}(2)-\mathrm{Ni}(1)-\mathrm{N}(1)$ & $98 \cdot 99(11)$ & $99 \cdot 11(17)$ & $0 \cdot 12$ \\
\hline $\mathrm{N}(2) \# 1-\mathrm{Ni}(1)-\mathrm{N}(1)$ & $81 \cdot 01(11)$ & $80 \cdot 89(17)$ & $-0 \cdot 12$ \\
\hline $\mathrm{N}(3) \# 1-\mathrm{Ni}(1)-\mathrm{N}(1) \# 1$ & $90 \cdot 53(11)$ & $90 \cdot 66(15)$ & $0 \cdot 13$ \\
\hline $\mathrm{N}(3)-\mathrm{Ni}(1)-\mathrm{N}(1) \# 1$ & $89 \cdot 47(11)$ & $89 \cdot 34(15)$ & $-0 \cdot 13$ \\
\hline $\mathrm{N}(2)-\mathrm{Ni}(1)-\mathrm{N}(1) \# 1$ & $81 \cdot 01(11)$ & $80 \cdot 89(17)$ & $-0 \cdot 12$ \\
\hline $\mathrm{N}(2) \# 1-\mathrm{Ni}(1)-\mathrm{N}(1) \# 1$ & $98.99(11)$ & $99 \cdot 11(17)$ & $0 \cdot 12$ \\
\hline $\mathrm{N}(1)-\mathrm{Ni}(1)-\mathrm{N}(1) \# 1$ & $180 \cdot 0$ & $180 \cdot 00(17)$ & $0 \cdot 0$ \\
\hline
\end{tabular}

The angle of this plane (II) $(\mathrm{C} 4, \mathrm{C} 5, \mathrm{C} 5, \mathrm{C} 1 \# 1$, $\mathrm{C} 2 \# 1$ and $\mathrm{C} 3 \# 1)$ to plane (I) (Nil, N1, N2, N1\#1, $\mathrm{N} 2 \# 1)$ is $24 \cdot 51$.
This difference in angle between the plane (Nil, $\mathrm{N} 1, \mathrm{~N} 2, \mathrm{~N} 1 \# 1, \mathrm{~N} 2 \# 1)$ of first coordination around metal ion and six-membered aromatic ring, that 
occurs during the conversion of compound $\mathbf{1}$ to $\mathbf{2}$, is not considerable. However, this minute change in conformation that may cause colour change, can not be ignored.

Comparison of bond lengths and angles in both compounds 1 and 2 has also been taken up in this regard. When compound $\mathbf{1}$ is converted to compound $\mathbf{2}$, there are some changes in bond angles and distances that are associated with the aromatic ring and coordinated thiocyanate ligands. These deviations are listed below in a tabular form (table 3). As shown in table 3 , there are minor deviations in bond distances and angles through out the structure. But the notable deviation is the positioning of the thiocyanate ion before and after the colour change. The $\mathrm{C}(7)-\mathrm{N}(3)-\mathrm{Ni}(1)$ angle (associated with nickel ion and coordinated thiocyanate ion) is 172.5 in compound 1 (violet crystals) and this is 171.9 in compound 2 (the yellow compound). Even though, apparently, this deviation is not much, the slight change in positioning the thiocyate ligand might cause the little change in orbital overlap and thereby the change in electronic states causing colour change from violet to yellow.

\section{Conclusion}

Even though, ortho-phenylenediamine (opda) complexes have been known for long time, the solid state properties of metal-opda complexes were less explored. We synthesized a very simple coordination compound $\left[\mathrm{Ni}^{\mathrm{II}}(\text { opda })_{2}(\mathrm{NCS})_{2}\right](1)$ in a one pot synthesis starting from nickel chlorode, $\mathrm{KSCN}$ and opda moleclue. We have shown that the blue violet crysals of compound $\mathbf{1}$ undergoes solid state convrsion to a yellow form (compound 2) on heating as well as on standing in the sunlight. Long standing of crystals of 1 at room temperature results in the colour change from violet to straw (yellow) with the formation of compound $\mathbf{2}$. The crystal structure analyses of compounds 1 and $\mathbf{2}$ show both compounds have identical structural features except some minor differences in some of their bond lengths, including the coordinated $\mathrm{NCS}^{-}$ligand. We believe that this slight structural modification is responsible for this colour change from blue violet (compound 1) to straw yellow (compound 2).

\section{References}

1. Corey E J and Bailar Jun J C $1959 \mathrm{~J}$. Am. Chem. Soc. 812620

2. Gollogly J R and Hawkins C J 1967 Aust. J. Chem. 202395

3. Gollogly J R and Hawkins C J 1969 Inorg. Chem. 8 1168

4. Saito Y 1968 Pure Appl. Chem. 1721

5. Jurnak F A and Raymond K N 1972 Inorg. Chem. 11 3149

6. Beddoe P G, Harding M J, Masom S F and Peart B J 1971 Chem. Commun. 1283

7. Dettayes L J and Busch D H 1973 Inorg. Chem. 12 1505

8. Niketic S R and Woldbye F 1973 Acta Chem. Scand. 27621

9. Gollogly J R and Hawkins C J 1970 Inorg. Chem. 9 576

10. Grenthe I, Paoletti P, Sandstrom M and Glikberg S 1979 Inorg. Chem. 182687

11. De G, Biswas P K and Ray Chaudhuri N $1984 J$. Chem. Soc., Dalton Trans. 2591

12. Mukherjee A K, Mukherjee M, Welch A J, Ghosh A, De G and Ray Chaudhuri N 1989 J. Chem. Soc., Dalton Trans. 997

13. Mukherjee A K, Mukherjee M, Ray S, Ghosh A, De G and Ray Chaudhuri N 1990 J. Chem. Soc., Dalton Trans. 2347

14. Pariya C, Ghosh A, Ray Chaudhuri N, Ghosh S and Mukherjee M 1996 Polyhedron 151643

15. Software for the CCD Detector System 1998 Madison, WI, Bruker Analytical X-ray systems Inc

16. Sheldrick G M 1996 SADABS, A program for absorption correction with the Siemens SMART area-detector system, University of Göttingen, Germany

17. Sheldrick G M 1997 SHELXS-97, A program for solution of crystal structures, University of Göttingen, Germany

18. Sheldrick G M 1997 SHELXL-97, A program for solution of crystal structures, University of Göttingen, Germany

19. Kabesova M, Boca R, Melnik M, Valigura D and Dunaj-Jurco M 1995 Coord. Chem. Rev. 140115

20. Greenwood N N and Earnshaw A 1989 Chemistry of the elements (Oxford: Pregamon Press) p. 343 